\title{
COMPREHENSIVE WATER MANAGEMENT SCENARIOS FOR STRATEGIC PLANNING
}

\author{
E. MANOLI \\ P. KATSIARDI \\ G. ARAMPATZIS \\ D. ASSIMACOPOULOS*
}

Selected from papers presented in $9^{\text {th }}$ International Conference on Environmental Science and Technology (9CEST2005)

1-3 September 2005, Rhodes island, Greece

\author{
Department II, School of Chemical Engineering \\ National Technical University of Athens \\ 9 Heroon Polytechniou st.,Zografou Campus \\ 15780 Athens, Greece
}

*to whom all correspondence should be addressed

Tel: +(30) 2107723218 ; Fax: +(30) 2107721196 e-mail: assim@chemeng.ntua.gr

\begin{abstract}
The assessment of the applicability and suitability of potential measures and instruments is crucial in the strategic planning of water resources management. This paper presents a methodology founded on scenario analysis for assessing potentially applicable water management options in a regional context with respect to their efficiency, extent of application, cost and environmental impact.
\end{abstract}

Formulation, analysis and evaluation of the different scenarios are performed through a developed GIS-based Decision Support System (DSS). Selected options can be simulated under varying availability and demand conditions, so as to monitor their performance and define the extent of their applicability. The behaviour of the water system is subsequently assessed and evaluated for each examined option in comparison to a baseline scenario. The evaluation, based on computation of indicators and multicriteria analysis, evolves around and reflects the principles of Integrated Water Resources Management, Economic Efficiency, Environmental Sustainability, and Social Equity. Temporal aggregation of indicator time series is conducted through the computation of appropriate statistical criteria. Additional aspects that are addressed concern the computation of the total cost incurred by water uses and provision of water services, including Financial (Direct) costs, Resource costs, and Environmental costs from pollution and (over) abstraction. Finally, indicator values can be used to derive a Performance Matrix, which permits the ranking of the identified options and the selection of those that are deemed most appropriate for the formulation of strategic plans.

Modelled management options pertain to four categories: Measures related with Supply Enhancement, introducing new structural interventions to increase water availability; Measures of Demand Management, aiming to control and limit water demands and wasteful water use; Regional Development measures, affecting socio-economic preferences and finally Institutional policies, such as alternative water pricing structures and economic incentives.

The methodology is demonstrated through an application in the case of Paros Island, Greece, where the developing tourist industry creates large seasonal peaks in water demand, requiring the selection of appropriate mitigation methods. Scenarios were formulated and evaluated for water management options identified by local Stakeholders and proposed in existing management plans.

KEYWORDS: Water resources management scenarios, Decision Support System, Multicriteria evaluation, Economic analysis. 


\section{INTRODUCTION}

Decision-making processes associated with water resource allocation and planning are complex, requiring multidisciplinary information for evaluating their effects on a social, economic and environmental level [1]. In the context of the EU Water Framework Directive, such a systematic evaluation of water management interventions should be performed for long planning horizon, simulating long-run accumulative effects and anticipating potential future changes and uncertainties. Sectoral approaches to water management issues are still dominant [2,3]. However, analysis of the potential effects of water management options and strategies, in relation to the need for combining regional economic growth and environmental sustainability goals, can only be achieved through complex, integrated planning of future alternatives [2,4,5].

Scenario analysis has been the subject of much debate and methodological elaboration since its widespread emergence as a strategic planning tool, following the first successful application by Royal Dutch/Shell in forecasting and dealing with the uncertainties that faced the oil industry in the 1970s. The scenario building process has since become accepted as a means of learning about the future through the understanding of the nature and importance of the driving forces that may affect it.

Scenario planning means making choices today, while having an understanding of how developments may turn out in the future. In that sense, a scenario is "a tool for ordering one's perceptions about alternative future environments in which one's decisions might be played out"[6]. To that end, scenarios can help the decision maker in turning towards paths and approaches that could otherwise be missed or avoided. Although scenarios are not akin to predictions, they can provide knowledge on potential futures and events, and unlike forecasting they present alternative images of these futures, without providing probabilistic estimates and analyses. In essence, scenarios promote preparedness for potential future problems.

Scenario-building approaches can be summed up into four major schools, depending on the target variable [7]:

1. Approaches maximizing differences, showcased by the Manoa approach by Wendy Schultz

2. Approaches maximizing focus, such as the mainstream approach by Peter Schwartz

3. Approaches maximizing depth, such as the Sociovision approach by Joop De Vries

4. Approaches maximizing development, such as the Harman Fan by Willis Harman.

These approaches can all be integrated into the strategy development process (Figure 1); maximising the differences is useful in determining the demand and availability parameters, maximising depth can be used in the development of appropriate responses, and maximising development can be used in the evaluation of a strategy as a whole (Figure 2). Following from the DPSIR Framework of analysis, which is commonly used in the assessment of water resources systems [8], scenarios can be built to encompass the entire water system, enabling the strategic planning of management interventions, or Responses.

Once the major Drivers have been identified, an approach that identifies potential trends in the Pressures applied on the water system can provide alternative developments in terms of the State of the water system and of the potential Impacts on Society and on the Environment. Appropriate Responses can then be selected to address the emerging conditions. 


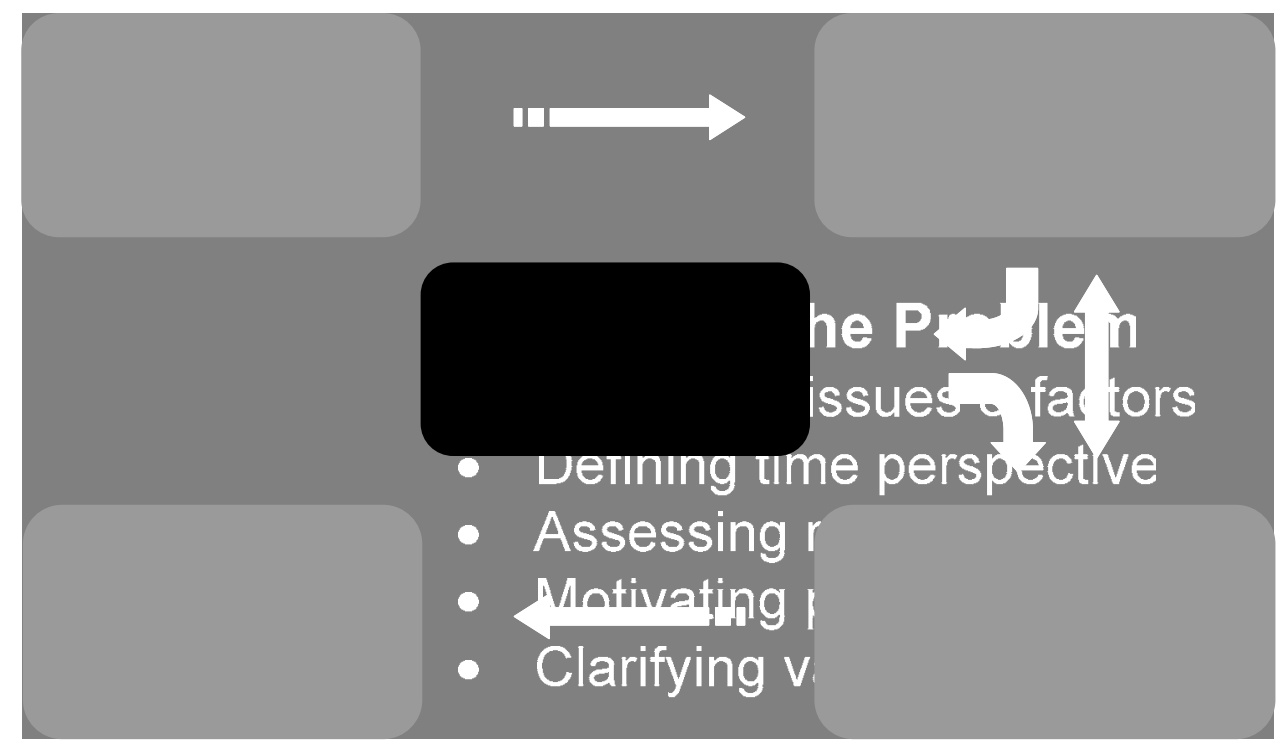

Figure 1. The Scenario Building Process

(adapted from Peter Schwartz: The Art of Long View)

Under this context, three types of Scenarios can be formulated; demand scenarios, addressing the uncertainty in the human environment, water availability scenarios, which address the uncertainty of meteorological conditions, and responses scenarios, which can examine the applicability and effectiveness of either planned interventions (or reference case scenarios), or new measures/policy instruments under different variables such as timeframe, location and magnitude.

The main objectives of scenario analysis undertaken in the present work were to determine the options effective in meeting set strategic targets, and estimate their potential extent of application, cost and environmental impact. Under this context, the analysis process is based on the concept of a "comprehensive scenario". Comprehensive scenarios consist of a hydrological (availability) and a demand scenario, which represent alternative future developments not directly affected by the decision-making process. As these are not cover the issue of supply and demand-side interventions, a third component is introduced, which reflects a selected management option to be evaluated in the examined case.

The scenarios were evaluated using a prototype GIS-Decision Support System (WSM DSS) developed for assisting in regional, strategic planning in the context of the economic principles and environmental sustainability objectives outlined in the WFD. The DSS emphasizes on the water stress problems and social conflicts arising in arid and semi-arid regions. The system is currently being applied to river basins and administrative regions in Greece, Italy, Cyprus, Portugal, Israel and Spain; however it can easily be extended to work with other regions [9]. The next paragraphs briefly describe the WSM DSS, and the approach is demonstrated through an exemplary application in a typical Greek island, Paros.

\section{DECISION SUPPORT SYSTEM OVERVIEW}

The prototype DSS [9] has been developed with the purpose of formulating alternative water management scenarios for water deficient regions. The DSS is able to model, simulate, analyse and evaluate alternative management responses, operating under the basic principle of promoting effectiveness, economic efficiency, environmental sustainability, and equity in the provision of water supply and the allocation of costs among the water system users. 
The WSM Decision Support System evolves around the DPSIR context [8] (Figure 2)and uses the concept of a water management scheme (WMS), defined as a set of scenarios for Driver variables (such as rainfall patterns and population growth) and the application of one or more water management interventions or instruments (Responses) in a suitable time frame.

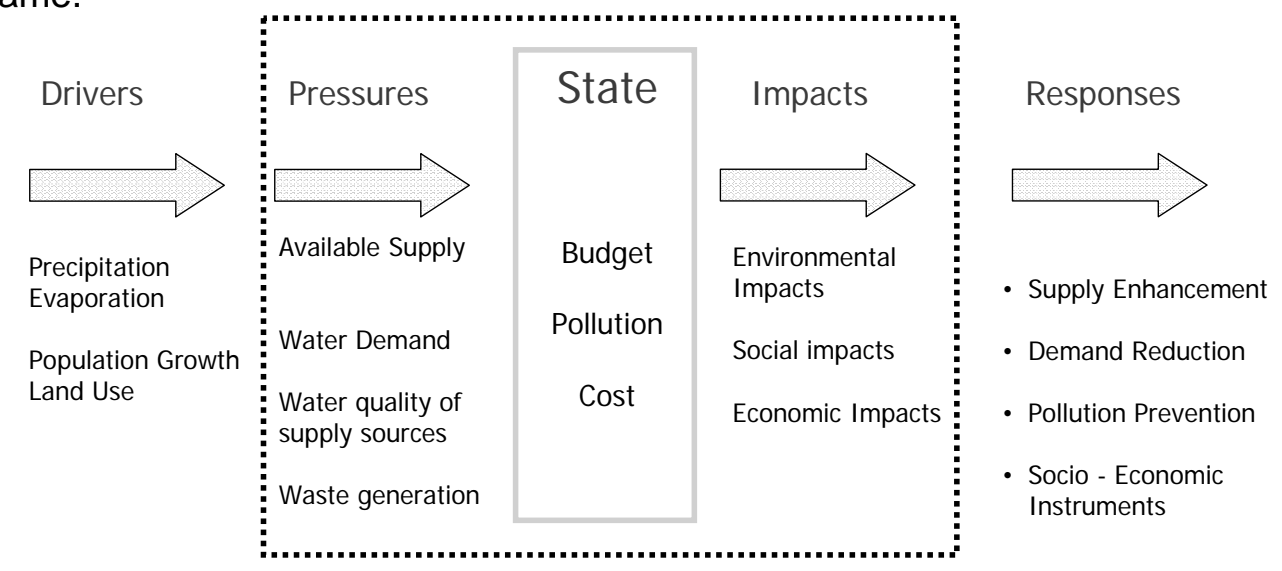

Figure 2. A Framework for Scenario Analysis in IWRM (Adapted from J. J. Walmsley: Framework for Measuring Sustainable Development in Catchment Systems)

The concept of the prototype DSS is based on the estimation of Pressures from the consecutive computation of future demand and availability time series and the forecast of the State of the water system through the simulation of water management strategies or single interventions. Then those can be compared, and the decision maker or the analyst can formulate responses to mitigate water stress impacts with respect to their objectives, economic or environmental. For this purpose, different models have been incorporated for estimating water availability, demand, allocation of available resources to different uses, and most importantly estimation of financial, environmental and resource costs. The latter are allocated to the particular water uses in accordance with the "polluter-pays" principle.

Water resource systems are modelled on the basis of geometric networks. A geometric network is described as a set of junctions (points) and edges (polylines) that are topologically connected to each other. In the Object Model junction elements are conceptualized as water nodes while the connections between them are the water links. Water nodes are classified into three categories, (a) supply nodes standing for alternative water supply sources and characterized by the monthly available supply, (b) demand nodes modelling water uses and flow requirements and, (c) transhipment nodes standing for treatment plants and generic network junctions. Water link objects are classified in four categories according to the connectivity rules of the system and the particular modelling requirements of the DSS, (a) supply links (pipelines and canals) conveying water from supply sources to demand nodes, (b) groundwater interaction links (recharge and discharge), representing the natural interaction between surface and groundwater bodies, (c) return flow links, conveying return flows from consumptive demand uses to receptor bodies (surface or groundwater) or wastewater treatment plants, and (d) river links, representing the natural course of a river water body.

\subsection{Water allocation and modelling of water management options}

Economic optimization models, aiming to maximize the social welfare surplus require the monetary valuation of environmental impacts, societal objectives, developmental priorities and property rights, which in most cases is subject to many constraints and limits the applicability of a tool. The WSM DSS simulation model for water allocation minimizes water shortage under limited water supplies [10]. In situations of water shortage, distributing the water available from the various supply sources to the connected uses 
creates conflicts. The allocation model solves this problem using two user-defined priority rules. First, competing demand sites are treated according to specified priorities. Those can express social preference or constraints, economic preference (prioritization to activities with highest economic values), or a system of water rights. In case that a particular use can be supplied by more than one resource, supply priorities are used to rank the choices for obtaining water. Supply priorities express cost preference; quality preference of uses (e.g. domestic or industrial use) for supply sources with high water quality; need for the protection of resources and the formation of strategic reserves.

Table 1. Summary Table of Policy Options and related Actions

\begin{tabular}{|l|l|}
\hline Policy Options & Actions \\
\hline Supply Enhancement & Unconventional/untapped resources \\
& Surface water exploitation (direct abstraction, dams, \\
& reservoirs, rainfall harvesting, conjunctive use) \\
& Groundwater exploitation \\
& Desalination \\
& Inter-basin transfer \\
& Water Reuse \\
\hline Demand & Quotas, Regulated supply \\
Improvement/Efficiency & Irrigation method improvements \\
& Conservation measures in the home \\
& Recycling in industry and domestic use \\
& Improved infrastructure to reduce losses (networks, storage \\
facilities) & Raw material substitution and process changes in industry \\
\hline Social-Developmental & Change in agricultural practices \\
Policy & Change of regional development policy \\
\hline Institutional Policies & Economic Policies (Water pricing, Cost recovery, Incentives) \\
\hline
\end{tabular}

An additional characteristic of the DSS is that it predefines a number of "abstract" water management measures and instruments (actions) and incorporates them as methods into the system. These actions (Table 1) modify accordingly the properties of the water system objects or introduce new ones, to respond to water infrastructure development. An "abstract" action becomes "application specific" by the user-definition of its magnitude, time horizon and geographic domain. Incorporated actions are mainly focused on options to deal with the frequent water shortages occurring in arid regions. Their main aim is to either enhance supply, mostly through structural interventions, or to regulate demand through the promotion of conservation measures, technological adjustments, or to consider pricing policies for achieving adequate recovery of costs and provide incentives for conservation.

\subsection{Evaluation and Economic Analysis}

Evaluation of alternative schemes takes into account the entire simulation horizon. Indicators are computed on three levels and are aggregated to an overall index using a bottom-up approach. On a first level, indicators are derived from the simulation results and computed for each component of the water resource system. On a second level these are spatially aggregated for the entire region (Table 2), to describe the overall behaviour in terms of environmental, efficiency, and economic objectives.

Then, second-level indicators are temporally aggregated on the basis of statistical criteria for reliability, resilience and vulnerability $[11,12]$. The statistical criteria express the behaviour of the monthly or yearly time series of each indicator with respect to a predefined range of satisfactory values that the indicator can assume. 
Reliability is defined as the probability that any particular indicator value will be within the range of values considered satisfactory. Resilience describes the speed of recovery from an unsatisfactory condition. Vulnerability statistical criteria measure the extent and the duration of unsatisfactory values. Performance for each indicator is computed as the product of the above criteria, and the relative sustainability index of each WMS is estimated according to multicriteria analysis, as the weighted sum of the performance of the selected indicators. This relative index can be used to rank alternative strategies or modelled actions according to the objectives of the undertaken analysis.

Table 2. Summary of second-level indicators in the DSS evaluation procedure

\begin{tabular}{|l|l|}
\hline Category & Indicator \\
\hline \multirow{4}{*}{$\begin{array}{l}\text { Resvironment } \\
\text { Eesources }\end{array}$} & Dependence on Inter-basin water transfer \\
\cline { 2 - 2 } & Desalination and reuse percentage \\
\cline { 2 - 2 } & Groundwater exploitation index \\
\cline { 2 - 2 } & Non-sustainable water production index \\
\cline { 2 - 2 } & Share of treated urban water \\
\hline Economics & $\begin{array}{l}\text { Coverage of Domestic, Environmental, Hydropower, Industrial } \\
\text { and Agricultural Demands/Requirements }\end{array}$ \\
\cline { 2 - 2 } & Direct Costs \\
\cline { 2 - 2 } & Benefits \\
\cline { 2 - 2 } & Environmental Cost \\
\cline { 2 - 2 } & Cost recovery rate \\
\hline
\end{tabular}

The evaluation can also be performed through economic analysis, based on the computation of financial, environmental and resource costs. Estimation of financial costs is rather straightforward, depending on data entered for the amortization of capital investments, specific energy consumption and cost, and other operation and maintenance costs associated with each part of the infrastructure [13]. Environmental costs are assessed using a practical model based on the concept of cost valuation (approximation of environmental costs through the measures required to prevent/mitigate environmental damage or achieve good status). Resource costs in the current assessment are approximated by the scarcity rent. The scarcity rent of water, (i.e. the rent per unit of a scarce resource - water in this case) is a surplus, the difference between the opportunity cost of water (equal to the market equilibrium price $P$ ) and the per unit (marginal) direct costs (such as abstraction, treatment and conveyance) of turning that natural resource into relevant products.

\section{APPLICATION OF THE DSS IN THE CASE OF PAROS ISLAND, GREECE}

The island of Paros, with an area of $196 \mathrm{~km}^{2}$ is one of the most popular tourist destinations in the Cycladic Complex in Greece. The island has a registered permanent population of 12,800 that is increased by as much as $300 \%$ during the summer months. The rapid development of the tourist industry in the last 30 years made the creation of new infrastructure necessary to cover the ever-increasing needs of the visitors and the lodging owners. The little-by-little infrastructure development took place without proper planning and control, leading to the current economic and environmental problems. The water demand growth of the last decades has been addressed mostly with extensive water drillings, both public and private, to supply the domestic and agricultural sectors. Paros is a typical case where the water shortage occurs on a seasonal basis. Tourism and irrigation demand reach their peak during the summer, creating conflicts between uses and problems with water supply adequacy during peak consumption. Domestic needs in the year 2004 are estimated at approximately $1.96 \mathrm{hm}^{3}$. Irrigation demand is estimated at approximately $2.5 \mathrm{hm}^{3}$. In a "business as usual" scenario domestic demand 
is estimated at $2.5 \mathrm{hm}^{3}$ in 2020 and $2.9 \mathrm{hm}^{3}$ in 2030, resulting in a total deficit (under average hydrology conditions) of $1.36 \mathrm{hm}^{3}$.

This analysis focuses on three interventions proposed by the local Water Utility, network unifications, desalination, and increase of water prices in order to achieve adequate cost recovery. The behaviour of the system under each option was assessed under the three baseline scenarios, incorporating also scheduled interventions. These are: (i) a combination of high demand and high frequency of dry years (BAU+HD), reflecting the worst scenario of shortage; (ii) a combination of reduced demand with a high frequency of wet years (LD+HW), reflecting the best case scenario; and (iii) a combination of high demand with a series of average years (BAU+Normal), to reflect the current trends of the system in a "business as usual" context. A specific set of indicators was selected, considered as representative of the management issues experienced in the region. Those are (a) Effectiveness vs. time for agricultural and domestic use, (b) Total direct cost associated with the provision of water services and the application of the different options, (c) Total environmental cost, incurred from pollution and (over)exploitation of groundwater resources.

\subsection{Intervention 1: Network Unifications}

The water supply network of Paros is highly fragmented, due to the past administrational structures governing the water supply. As a result, there are a number of separate water supply networks that are each supplied by local resources. A more equitable allocation of resources can be achieved through network unifications. Under average availability conditions, the measure can lead to an increase in domestic demand coverage, an effect that is more pronounced under increased precipitation (Figure 3a). The effect becomes smaller as demand increases, because larger water quantities are required for satisfying local needs before water transfer, and no additional water supply sources have been introduced in the system. Overall the option is not very expensive, since the unifications proposed are between neighbouring municipal departments and construction costs, according to the local Water Utility, are low. Additional financial cost is incurred from the augmentation of water distributed (pumping requirements) but under any scenario this increase does not exceed $2 \%$ of the respective reference scenario present value (Figure $3 b)$. The increase of costs under the LD+HW scenario is much lower, since expensive connections between distant municipal departments are not required.

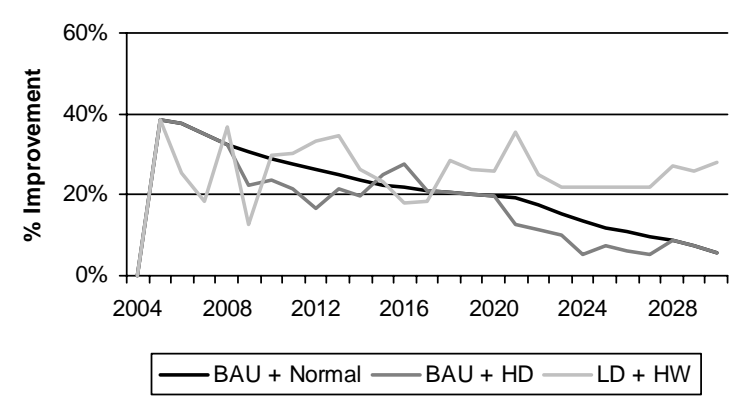

(a)

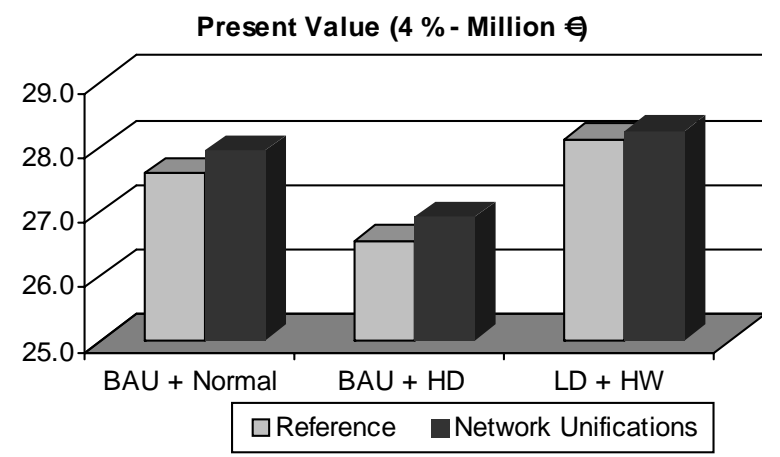

(b)

Figure 3. Example of results obtained from the simulation of network unifications (a) \% improvement of domestic demand coverage (b) comparison of financial costs

\subsection{Intervention 2: Desalination}

Desalination is the structural solution that performs the best among all examined. Due to the design targets, domestic demand coverage does not fall below 95\% with the exception of a dry period (BAU+HD scenario-Figure 4a). The domestic deficit improvement with respect to each reference scenario is subject to the high hydrological variations; improvements are lower under the LD+HW scenario where due to high water 
availability and decreasing demand trends, the domestic deficit is lower. Despite the observed improvement and the recent technological advances, which lower energy consumption and costs, desalination remains a very expensive solution. In all cases an at least $30 \%$ increase of costs is anticipated if a strategy shall predominantly rely on desalination (Figure 4b). A combination of the option with other, mostly non-structural solutions should therefore be preferred in an effort to limit the required capacity, and avoid incurring very high additional costs to consumers.

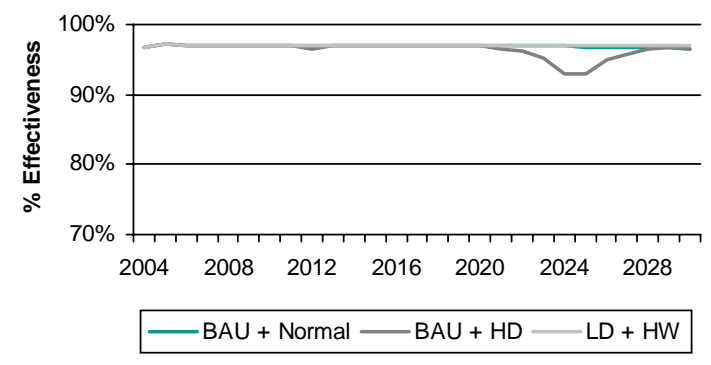

(a)

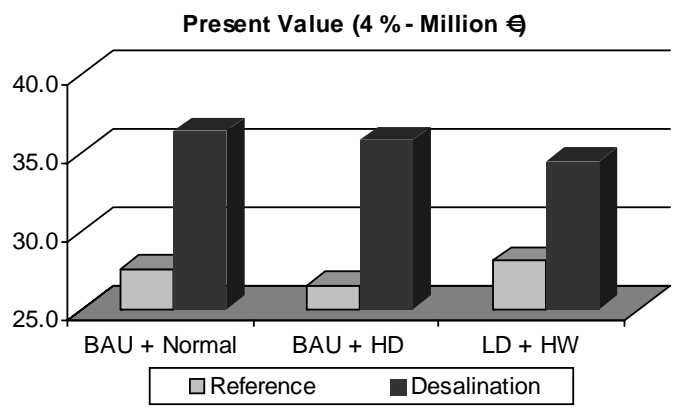

(b)

Figure 4. Example of results obtained from the simulation of desalination (a) \% domestic demand coverage (b) comparison of financial costs

\subsection{Intervention 3: Domestic water pricing}

Although the management of domestic water supplies is the responsibility of one single authority, prices throughout the island are not uniform. The current weighted average selling price is at approximately $1.45 € / \mathrm{m}^{3}$. In order to estimate the effect that a price increase would have on demand a small elasticity of -0.2 was assumed for residential and tourist consumption. The pricing scheme that was examined was a gradual increase (every two years) of average prices from $1.6 € / \mathrm{m}^{3}$ to $2.5 € / \mathrm{m}^{3}$. The significant domestic demand decrease, due to the rather high augmentation of prices directly affects domestic demand coverage effectiveness (Figure 5a). Especially under the LD+HW scenario, effectiveness after 2007 is stabilised above $90 \%$. Similarly, irrigation deficits are reduced, reaching almost a $10 \%$ relative improvement under the BAU+Normal and LD+HW scenario. Consequently, the reduction of supply delivered to domestic use incurs a financial cost decrease, which can reach even the $13 \%$ of the present value of the corresponding reference case. Total environmental costs present a small decrease, since in some aquifers unsustainable groundwater abstractions are reduced.

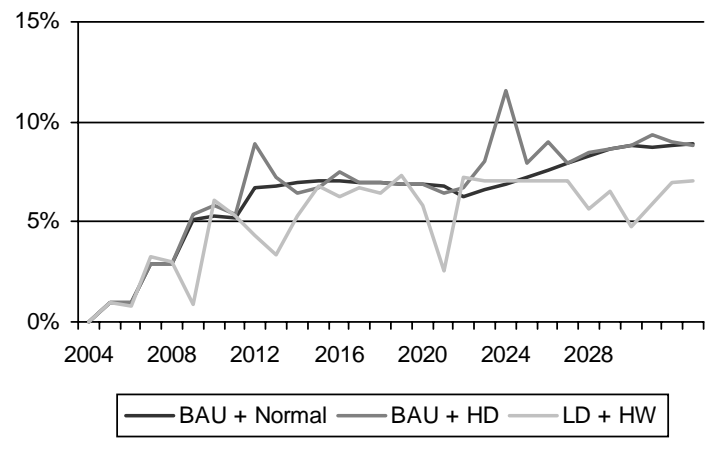

(a)

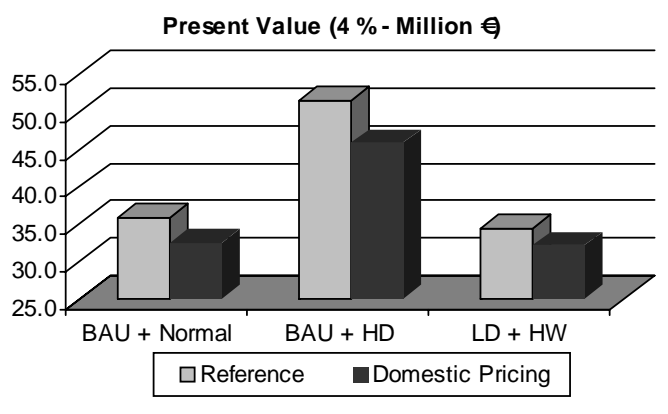

(b)

Figure 5. Example of results obtained from the simulation domestic water pricing (a) \% improvement of domestic demand coverage (b) comparison of environmental costs

The most effective combination of measures is selected according to their performance. Results for the three baseline scenarios were combined and normalized in a scale from 0 
to 5 in order to obtain a preliminary ranking. The obtained matrix, in numerical and normalised is presented in Table 3. The reference case presented in the matrix refers to the combined average results from the three reference scenarios, while the relative sustainability index for demand coverage includes the equally weighted performance for domestic and agricultural use.

Table 3. Option performance matrix

\begin{tabular}{|c|c|c|c|}
\hline Option & $\begin{array}{l}\text { Relative Sustainability } \\
\text { Index for Demand } \\
\text { Coverage }\end{array}$ & Financial Cost & $\begin{array}{c}\text { Environmental } \\
\text { Cost }\end{array}$ \\
\hline Reference Cases & $0.008(-)$ & 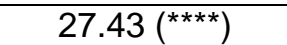 & $40.66(-)$ \\
\hline Network Unifications & $\left.0.1544^{(* *}\right)$ & $27.57(\star \star \star \star)$ & $39.16(* *)$ \\
\hline Desalination & $0.366\left(^{(\star \star \star \star \star}\right)$ & $35.57\left(^{*}\right)$ & $39.27\left(^{* *}\right)$ \\
\hline Domestic Pricing & $0.218(\star \star \star)$ & 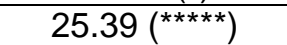 & $\left.38.86^{(* \star}\right)$ \\
\hline
\end{tabular}

\section{CONCLUDING REMARKS}

In conclusion, it can be said that the scenario formulation process is a learning process, and one that teaches the participant to commit to a creative and imaginative way of thinking about the future. The scenarios should reflect their creator's vision, their mission, and their overall strategy in approaching the issue at hand. In terms of the strategic planning of water resources systems, a development of adequate and complete scenarios can contribute to achieving a maximum degree of efficiency in the supply and allocation of the resources and in the rational use of the resource, to achieving sustainability of the existing resources, and to minimising the costs involved while at the same time promoting economic development.

Furthermore, it should be noted that the definition of appropriate management options applicable to water-stressed regions is highly dependent on regional conditions, and should be based on a coherent estimation of their potential effect under a variety of conditions determining the State of the water system. Indicators selected should be comprehensive and serve as a basis for the selection and scheduling of appropriate measures under different hydrology and socio-economic conditions.

Although an analysis of this type can only be subjective and requires many assumptions for costs, benefits, ecological and social responses, and environmental costs, the approach implemented in the presented DSS is simple enough and can easily be extended to other cases.

\section{REFERENCES}

1. Salewicz K.A. and Nakayama M. (2004) 'Development of a web-based decision support system (DSS) for managing large international rivers', Global Environmental Change, 1 sup. 1, 25-37.

2. McKinney D.C, Cai X, Rosegrant M.W., Ringler C. and Scott C.A. (1999) Modeling Water Resources Management at the Basin Level: Review and Future Directions, International Water Management Institute, SWIM Paper 6.

3. Salman A.Z., Al-Karablieh E.K. and Fidher F.M. (2001) 'An Inter-Seasonal Agricultural Water Allocation System (SAWAS)', Agricultural Systems, 68, 233-252.

4. Bouwer H. (2000) 'Integrated Water Management: Emerging Issues and Challenges', Agricultural Water Management, 45, 217-228.

5. Albert X., Mark O., Babel M.S., Gupta A.D. and Fugl J. (2001) 'Integrating Resource Management in South East Asia', Water21, October 2001, 25-30.

6. Schwartz P. (1996), 'The Art of the Long View: Planning for the Future in an Uncertain World', Currency Doubleday, Bantam Doubledat Dell Publishing Group Inc., New York.

7. Schultz W., 'Infinite Futures', Accessed on November $16^{\text {th }} 2005$, http://www.infinitefutures.com/ 
8. Walmsley J. (2002), 'Framework for measuring sustainable development in catchment systems', Environmental Management, 29, 2, 195-206.

9. WaterStrategyMan (2002-05), 'Developing Strategies for Regulating and Managing Water Resources and Demand in Water Deficient Regions', EU DG Research, EVK1-CT-200100098, URL: http://environ.chemeng.ntua.gr/wsm/

10. Manoli E., Arampatzis G., Pissias E., Xenos D., and Assimacopoulos D. (2001), 'Water demand and supply analysis using a spatial decision support system' Global NEST: The International Journal, 3, 199-209.

11. Bogardi J.J. and Verhoef A. (1995), 'Reliability Analysis of Reservoir Operation', In: New Uncertainty Concepts in Hydrology and Water Resources, Cambridge University Press.

12. Task Committee on Sustainability Criteria, Water Resources Planning and Management Division, ASCE and Working Group of UNESCO/IHP IV Project M-4.3 (1998), Sustainability Criteria for Water Resource Systems, ASCE Publications, Virginia.

13. WATECO (2002), Economics and the Environment - The implementation challenge of the Water Framework Directive, A guidance document, European Commission. 